\title{
Régis DEBRAY, Aveuglantes Lumières
}

Paris, Gallimard, 2006, 208 p., ISBN 2-07-078256-5, $16.90 €$.

Michel Vovelle

\section{CpenEdition}

Journals

Édition électronique

URL : https://journals.openedition.org/ahrf/11269

DOI : 10.4000/ahrf.11269

ISSN : 1952-403X

Éditeur :

Armand Colin, Société des études robespierristes

Édition imprimée

Date de publication : 1 septembre 2007

Pagination : 206-207

ISSN : 0003-4436

Référence électronique

Michel Vovelle, «Régis DEBRAY, Aveuglantes Lumières », Annales historiques de la Révolution française [En ligne], 349 | juillet-septembre 2007, mis en ligne le 29 décembre 2009, consulté le 01 juillet 2021. URL : http://journals.openedition.org/ahrf/11269; DOI : https://doi.org/10.4000/ahrf.11269 
Régis DebraY, Aveuglantes Lumières, Paris, Gallimard, 2006, 208 p., ISBN 2-07-078256-5, 16.90€.

Au lycée, dans ma jeunesse, on récitait ses classiques. De la révolte romantique du jeune Musset dans Stellio, j'ai retenu la rengaine : « Dors-tu content Voltaire, et ton hideux sourire... ". J'avoue que j'ai oublić la suite.

Mais voilà un débat classique que cet essai de Régis Debray tente de réchauffer, en affichant l'impertinence. Affrontant la pensée commune, à gauche du moins, l'auteur assure prendre des risques - je les crois limités, il sera reçu, au pire avec le sourire, si j'en juge par le compte rendu à peine ironique que lui a réservé Marc Fumaroli dans Le Monde (7 décembre 2006).

Déclarant prendre Voltaire comme " tête de turc " il n'ajoute rien au réquisitoire sur le personnage - intéressé, vaniteux, intégré dans le système - que nous ne sachions déjà, et d'ailleurs, c'est à Émile Faguet, ce vicux cheval de retour, qu'il emprunte une page qui fleure bon les littératures de mon enfance, sur le thème scandé : « c'est un Français », léger, gracieux, malicieux, qui se croit novateur mais ne comprend pas la liberté. Voltaire qui fait l'éloge de la "mosaïque Europe » méconnaît ou sous-estime les guerres, comme les autres philosophes, il est au service des despotes qu'il flagorne. De sa critique «le feutré et le moucheté en bonne compagnie » (p. 43) n'a pas résisté à la marche de l'histoire.

Tout ceci, pourrions-nous dire, Robespierre l'avait déjà dénoncé en 1794 dans une invective célèbre sur les philosophes de la génération passée qui rampaient dans les antichambres des rois et, depuis deux siècles, assassines ou érudites les monographies se sont multipliées sur les bas ou petits côtés du patriarche de Ferney et la déconstruction de sa légende.

D'un conformisme navrant, l'identification Voltaire - Lumières dans toute la tradition cléricale et réactionnaire du siècle passé m'attriste moins que le choix de Mozart comme seconde tête de turc. Trop sucrés les raisins de l'année Mozart, et bons pour les goujats ? C'est ainsi en tout cas que notre anti-snob, enfilant des phrases d'anthologie, évoque le " chérubin des Lumières [qui] nous fait miroiter l'heure exquise ", " une pastorale sans Hitler ni Staline " (quelle ignorance crasse !)... ni problème des banlieues. "Monde jardin ", " nom bien fleuri " que celui de La Flûte Enchantée, et pour tout dire « quoi de plus nunuche » que le dénouement de Don Giovanni ? Régis Debray révèle aux naifs qui restaient sous le charme, que Mozart n'a pas " cassé le pot au lait ", que son effronterie n'est que d'apparence, sous les traits de Figaro, que «Viva la libertà » ne saurait concerner que les aristocrates, et last but not least (j'en passe et des meilleures) que Mozart ignore la populace, les cachots et les piques : "Il n'a rien deviné de l'âge des foules ni des noirs tressaillements de 93-94 ". Franc-maçon de convention, "chrétien en liesse " à la recherche du " plaisir sexuel, esthétique, gastronomique », c'est un Mozart quasiment vu à travers le film Amadeus qui nous est transmis par notre brillant critique. Je savais tout cela, mais je me sens bien naif de m'être laissé mystifier si longtemps.

Mais aussi trop c'est trop : après les sirops de l'annće Mozart, l'esthète anticonformiste n'a pu échapper au matraquage consensuel sur les Lumières en 2006 : colloques à Nancy ou ailleurs, maxi exposition à Paris... même s'il convient de prendre des gants (avec « l'excellent commissaire "Tzvetan Todorov), c'est l'objet même de l'invective qui se dévoile, une fois esquichées les deux potiches emblématiques, Voltaire et Mozart. Et là, il faut sc forcer quand on a si longtemps combattu dans ce camp, fût-ce dans le « clair obscur », pour enfin 
dénoncer sans détours l'illusion de la raison, cette « présomption que le vrai jouit d'une compétence universelle, que le faux est la part maudite d'insanité qui ne saurait survivre à la propagation des rayons de la raison ». Sec rationalisme des Lumières, qui ne connaît point d'entrée, " humiliation " alors qu'aujourd'hui le mur est entre « humiliants et humiliés », son messianisme mal déguisé de la marche au bonheur a méconnu le "sacré social ": faute d'observer le feu sacré, on prend le refoulé en pleine figure et on se retrouve les quatre fers en l'air : Condorcet et ses semblables, avec leur " déconcertant strabisme politique ", car « rien de ce qui depuis la Grande Peur de 1789 a fait épidémie en mettant le feu aux poudres et la guillotine sur pied n'avait représenté un sujet digne d'intérêt pour les cervelles emblématiques ».

La Révolution : nous y voilà. Lauteur sait de quoi il parle pour l'avoir pratiquée dans sa jeunesse, et il est autorisé à dénoncer la conjonction « en bois » de la formule " la Révolution et les Lumières », ce et « mat et machinal " qui gomme le hiatus entre Voltaire et Robespierre, confond le « jabot » du premier et la «blouse » (?) de Carnot. Qu'y a-t-il de commun entre l'« ironiste du boudoir » et le « doctrinaire au hachoir » qu'est Marat ? À nouveau Régis Debray ne peut se retenir en évoquant après 89 le "dégagement de chaleur [...] des journées révolutionnaires, les rots et les pets du gros animal " qui ont « fait tourner les chocolats de la bergerie ». En deux mots « un monde où on chante La Marseillaise ressemble aux Lumières non comme un papillon à sa chrysalide mais comme l'apocalypse à la pentecôte ou un Goya de la maison du sourd à un Greuze ».

Et Rousscau direz-vous, ce mal-aimé de la postérité, n'est-il pas là pour assurer quelque continuité dans l'héritage... ? Si sans doute " le guindé, le blafard, le cireux, disons le Comité de Salut public, n'est-il pas sans rapport avec un JeanJacques réduit à l'os... ? » Avec équanimité, c'est Robespierre qui en prend désormais pour son compte.

Naïvement, nous attendions la Révolution pour racheter l'imposture des Lumières : le seul mérite que l'on peut leur reconnaître, c'est d'avoir fait charnière entre les révolutions religieuses des millénarismes ensauvagés du XVI ${ }^{c}$ au XVII siècle et les révolutions universalistes et discursives dont le cycle, du jacobinisme au communisme, a achevé de s'étouffer désormais.

Aujourd'hui les Candide que nous sommes n'ont plus le choix qu'entre deux façons de vivoter : soit l'attente des frissons d'apocalypse qui n'auront jamais lieu (cette révolution mondiale dont rêvent encore les dernières générations d'hypnotisés par 1917), soit le soin de ses laitues dont Julien Gracq, le vieux sage que visite notre auteur, l'entretient, sans se cacher qu'un jour ou l'autre, la catastrophe viendra saccager nos plates-bandes. Mais au détour d'une allée, notre philosophe lucide ne risque-t-il pas de se trouver nez à nez avec le patriarche qu'il a malmené et qui a délivré le premier la prescription : "Cultivons notre jardin "?

Régis Debray se défend de hanter les salons et les antichambres, mais d'un colloque à une commission ou une rencontre civique, le voici réduit à promener l'idée " ingrate " d'une " gauche tragique » qu'il prêche dans le désert. S'il avait, dit-il, choisi Danton pour pseudonyme du temps de ses campagnes, c'est comme « un phare dans la pénombre ». Parce qu'il n'y a plus d'espérance collective, il a décidé d'éteindre les Lumières, et de naviguer dans le clair-obscur.

Michel Vovelle 